\title{
sciendo Analysis of ergonomic work equipment lowering the static load based on trend of development of work activities
}

doi:10.2478/mape-2019-0005

Date of submission to the Editor: 04/2018

Date of acceptance by the Editor: 07/2018

MAPE 2019, volume 2, issue 1, pp. 53-61

\author{
Blanka Horváthová* \\ ORCID ID: 0000-0002-1358-4573 \\ L'uboslav Dulina \\ ORCID ID: 0000-0002-5385-7476 \\ Eleonóra Bigošová \\ ORCID ID: 0000-0002-3946-3614 \\ Miroslava Barbušová \\ ORCID ID: 0000-0002-2654-1564
}

Martin Gašo

ORCID ID: 000-0003-0926-2923

University of Zilina, Slovak Republic

\section{INTRODUCTION}

Almost every worker is faced with some static load being affected to some extent. Often, he is not aware of the negative effects and consequences of staying in the wrong, but possibly comfortable, static position for more extended periods of activity. As industrial developments are inexorably moving towards increasingly massive automation and digitization, the majority of workers spend most of their working hours behind the computer. For these reasons, it is crucial to choose the right working equipment that meet the ergonomic and physiological requirements of the individual. Office chairs are one of the essential tools for working at a computer. Therefore, with our research team at the Department of Industrial Engineering at the University of Zilina, we focused on market research in the ergonomic chair segment, which would provide necessary information for the design of an ergonomic office workplace.

\section{BASICS OF RESEARCH}

To optimize human activity and eliminate physical load, industrial engineering, as well as ergonomics, seek to reduce the distance and frequency of movements to the lowest possible level. This low level of movements ensures their economic efficiency and, at the same time, allows for a smooth flow of production without unnecessary downtimes. On the other hand, the standardization of movements and the working space where the worker has everything at hand is heading towards increasing the static component of the work (Fig. 1).

\footnotetext{
*blanka.horvathova@fstroj.uniza.sk
} 


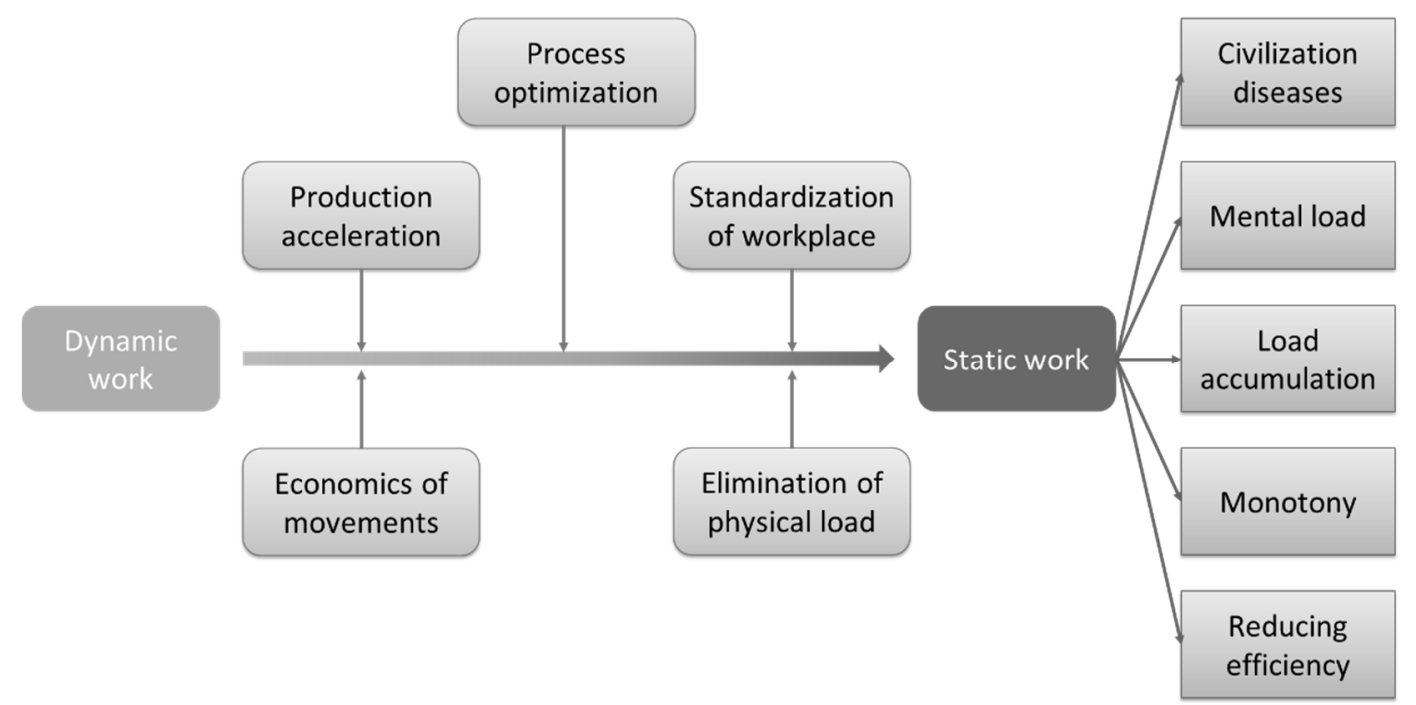

Fig. 1 Consequences of work activities optimization

Source: (Horváthová, 2019).

To optimize human activity and eliminate physical stress, industrial engineering, as well as ergonomics, seek to reduce the distance and frequency of movements to the lowest possible level. This low level of movements ensures their economic efficiency and at the same time allows for a smooth flow of production without unnecessary downtimes (Bubeník, 2004, Krajčovič, 2012) On the other hand, the standardization of movements and the working space where the worker has everything at hand is heading towards increasing the static component of the work.

\section{METHODOLOGY OF RESEARCH}

Currently, the number of sedentary professions in industrial enterprises is increasing. The automotive industry accounts for $44 \%$ of Slovakia's total industrial production, and in 2018 it reached 13\% of GDP (Kvašňák, 2018). Based on these facts and the structure of the Slovak economy, we conducted a survey on the increasing number of sedentary jobs in a manufacturing company supplying automotive components. We assume that by conducting the survey, we confirm the fact that the number of sedentary professions in industrial enterprises is growing, and that we highlight the associated health risks associated with this type of work activity. Organizational structure analysis was carried out in the company, focusing on dominant working positions in individual professions:

1. Professions which are performing work in the sitting position.

2. Professions which are performing work in a standing position.

Based on the results of the analysis of the representation of sedentary professions in the company, an analysis of the Slovak market was carried out, focusing on the offer of ergonomic chairs. These chairs, as already indicated by them, should meet the ergonomic requirements and eliminate the static load on the worker when performing a sedentary job. Chairs with the designation "ergonomic" or "health" were selected for analysis. The observed factor was modularity and the possibility of adjusting the essential elements of the chair - seat, backrest, lumbar support, forearm, and head restraints. The possibility of adjusting the height, depth, and angle of the parts of the chair was followed. The next monitored parameter was chair dynamics. The dynamic 
seat option was monitored to allow regular change of the working positions. Sitting on such a chair has proven to reduce the tension of large back muscle groups while reducing the static load in the lumbar spine.

\section{RESULTS AND DISCUSSION}

An analysis of the representation of sedentary professions was carried out in a company with 892 employees. Based on the analysis of professions from the organizational structure and the subsequent observation of individual work activities, 25 professional groups were generated. Specific professional groups combine the specializations of professions from all sections of the business that share common features. The number of employees of the enterprise in each occupational group and the dominant working positions is given in Table 1.

Table 1

Representation of basic working positions among the professions carried out in the production plant

\begin{tabular}{|c|c|c|c|}
\hline \multirow[t]{2}{*}{ Professional group } & \multirow{2}{*}{$\begin{array}{c}\text { Number } \\
\text { of employees }\end{array}$} & \multicolumn{2}{|c|}{ Primary working position } \\
\hline & & seating & standing \\
\hline Administrative worker & 8 & $\bullet$ & \\
\hline Analyst & 1 & $\bullet$ & \\
\hline Assistant & 3 & $\bullet$ & \\
\hline Auditor & 1 & $\bullet$ & \\
\hline Seasonal worker in administration & 13 & $\bullet$ & \\
\hline Logistics worker & 20 & $\bullet$ & \\
\hline Worker at the milling-cutter & 2 & & $\bullet$ \\
\hline Designer & 78 & $\bullet$ & \\
\hline Line manager & 1 & & $\bullet$ \\
\hline Project coordinator & 13 & $\bullet$ & \\
\hline Modelmaker & 3 & & $\bullet$ \\
\hline Assembly worker & 355 & & - \\
\hline Purchaser & 14 & $\bullet$ & \\
\hline Toolmaker & 38 & & $\bullet$ \\
\hline Manager of shifts & 11 & & $\bullet$ \\
\hline Scheduler & 6 & $\bullet$ & \\
\hline ICT worker & 9 & $\bullet$ & \\
\hline Product manager & 1 & $\bullet$ & \\
\hline Project manager & 7 & $\bullet$ & \\
\hline Trainer & 2 & • & \\
\hline Specialist (sum of all specializations) & 145 & $\bullet$ & \\
\hline Technical worker (IE and design) & 4 & $\bullet$ & \\
\hline Technical worker (technical section) & 5 & $\bullet$ & \\
\hline Manager & 74 & $\bullet$ & \\
\hline Machine adjuster & 78 & & $\bullet$ \\
\hline
\end{tabular}

Souce: autors - results of analysis and observation in the selected company.

As can be seen in Table 1 in the company under review, although it is an industrial production enterprise, most employees have sedentary jobs; $78 \%$ of employees perform sedentary professions. However, increasing the proportion of work activities with the predominantly static seated working position does not only concern industrial production. This growing trend affects all areas of working life, starting with the positions of programmers, through management positions and ending with students (Sasik et al., 2016). So, it can be said that the majority of working hours of most jobs are spent in the seated position.

In order to compare the results, an analysis of the Slovak professions catalogue was carried out at the same time as the company survey. These are the professions most 
frequently registered in the labour market in all sectors. Fig. 2 shows the number of professions with the primary seating working position respectively standing working position across industries.

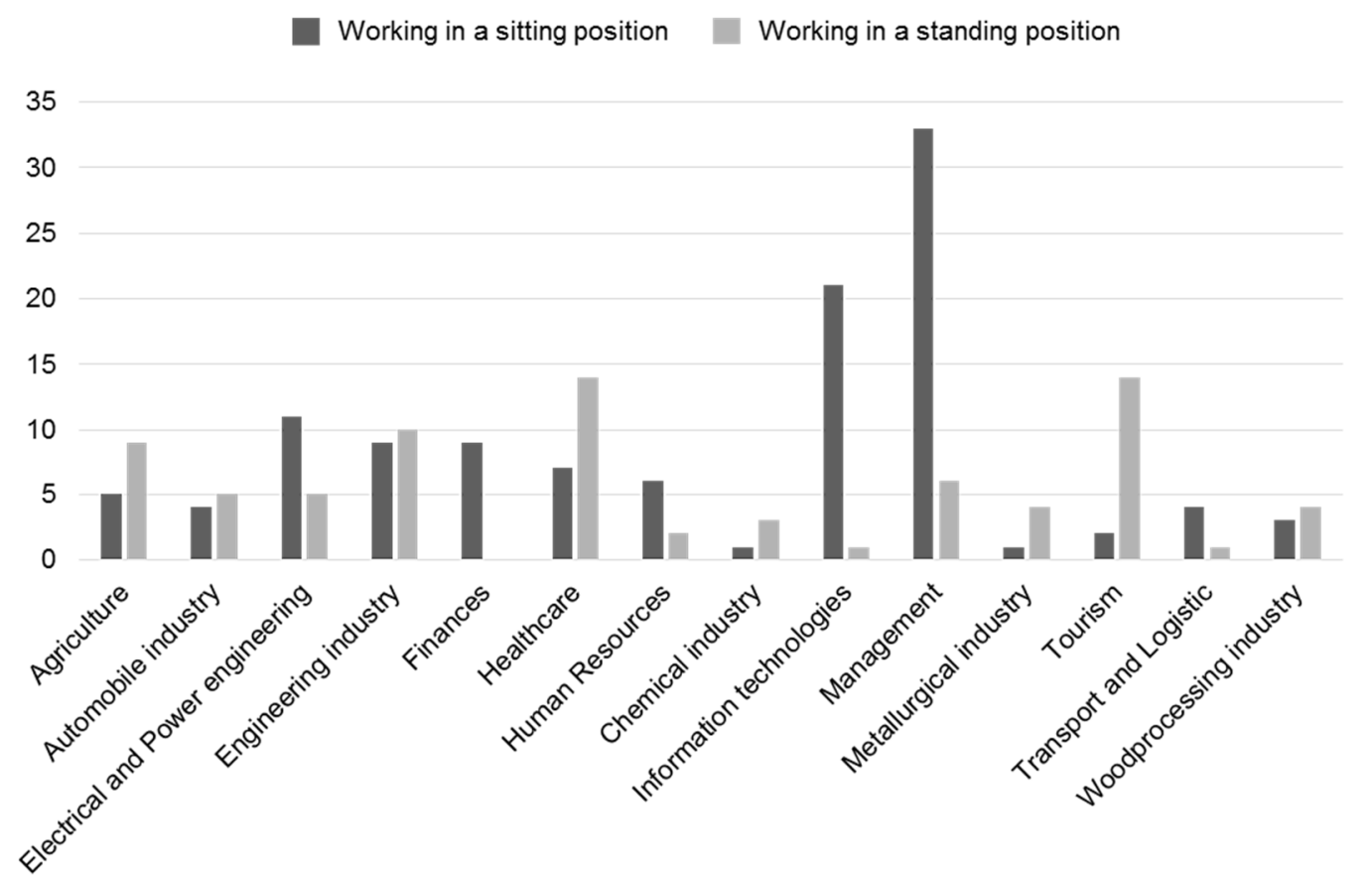

Fig. 2 The number of the most frequently registered professions in Slovakia with the sitting and standing working position

For comparison, Fig. 3 graphical representation of the percentage of sedentary professions in the monitored enterprise and among the professions in Slovakia.

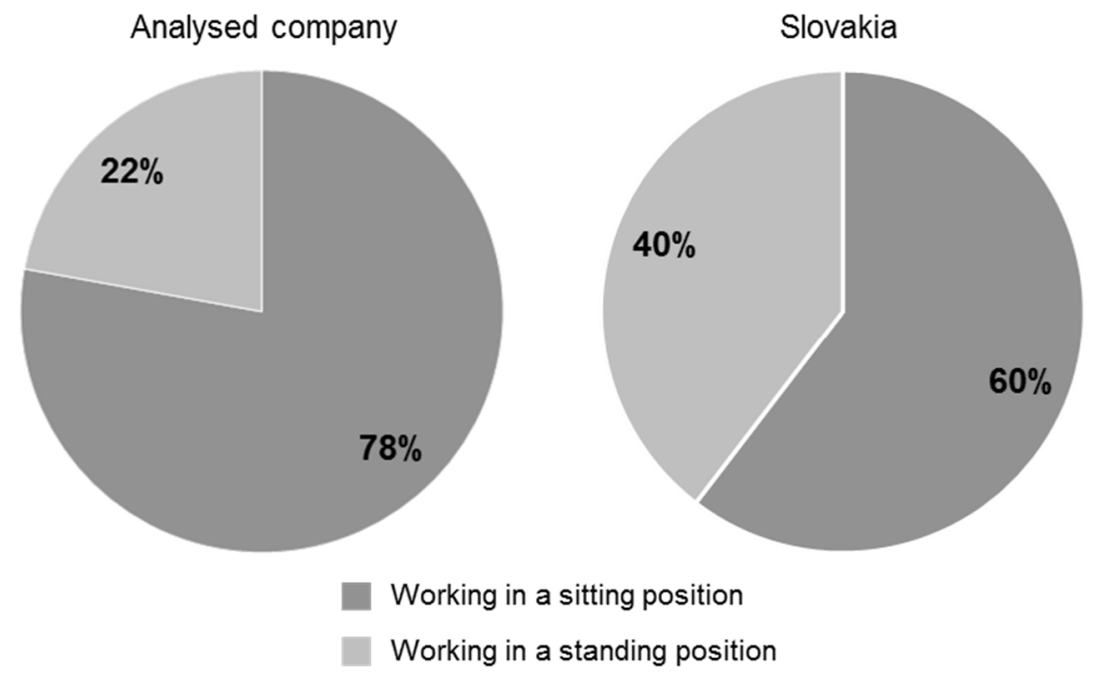

Fig. 3 Comparison of sedentary professions to among the most frequently registered professions and in the monitored enterprise

The survey shows that professions whose performance is predominantly in the seated working position have a majority representation in Slovakia. From the point of view of industrial ergonomics, this knowledge is essential. Currently, industrial ergonomics is mainly concerned with the identification of risk factors associated with manual work 
and manual material handling. However, as shown by this pilot survey, work activities are gradually transformed from manual to a psychic, and their performance is closely linked to computing; in a predominantly static sitting position. In the Slovak legislation, there is currently no definition of the static load arising from long-term work in a physiological working position such as sitting. The reason for this absence is the fact that according to the legislation of the Slovak Republic, sitting or standing working position or alternating alternatives are considered acceptable working positions (Decree, 2007). It is therefore acceptable for long-term work. As mentioned in the previous section, epidemiological studies point to the negative impact of sedentary employment on the spine, muscles, cardiovascular system, and thus on the worker's performance. In general, there is a reduction in blood flow in stressed areas under static load, thereby reducing the oxygenation of the muscles needed to maintain static positions (Salvendy, 2012). It is scientifically proven that the load on the lumbar spine - the transition between the $L$ and $S$ spine segments is more significant in the seated position compared to standing (Andersson et al., 1975). When standing upright, the spine forms an active path for even load distribution. However, at the seated position, the force distribution mechanism is changed, the load is applied to the intervertebral discs and as a result of their compression a higher risk of damage is created. Significant influence is also on the human cardiovascular system. At the sitting position, the veins in the knee area are compressed and blood circulation in the lower limbs is reduced.

The accumulation of static load and the resulting fatigue or health problems can be minimized by re-dynamizing work. There are two ways in which to work dynamically in sedentary jobs, which can release large muscle groups of the back while increasing blood circulation in the muscles:

1. Regular change of position - from sitting to standing. However, such a fundamental change of position requires the introduction of height-adjustable work tables and an increase in working space.

2. Regular positioning through dynamic sitting - dynamic sitting, or dynamic chairs, are based on the analogy of sitting on a therapeutic ball. An unstable pad ensures muscle activation to maintain balance and thus improves blood circulation in the muscles.

Based on the increasing number of sedentary professions, the expert team decided to conduct a survey of the ergonomic chairs offered. On the Slovak market, there are currently offered chairs with ergonomic or health markings, which, as the producers say, should alleviate the static load on the worker performing long-term sitting work. Slovak legislation determines the minimum requirements for the parameters of the essential parts of the office. For an office chair, it defines adjustable seat height, seating area interval, backrest height and tilt adjustment, and forearm height adjustment (Regulation, 2006). New parameters were added to these basic parameters, which were generated by an expert team based on ergonomic knowledge and discussion with physiology experts. The monitored parameters, which should be fulfilled by office chairs labeled ergonomic or health, were:

- Seat height adjustment;

- Variable seat depth;

- Seat back inclination independent of the backrest;

- The backrest slope; 
- Adjusting the backrest height;

- Adjusting the height of the lumbar support;

- Adjustment of lumbar depth;

- Height adjustable forearm rest;

- Adjusting the armrest angle;

- Presence of head restraint;

- Dynamic sitting.

The expert team analyzed the presence and modularity of the parameters in 41 chairs. Chairs from OFFICE PRO, SpinaliS, Asana, Spinergo, Topstar, Therapia and Maya were used to process statistics. The percentage of parameters in the total number of chairs monitored is shown in Fig. 4. The number of chairs depending on the number of fulfilled parameters is shown in Fig. 5.

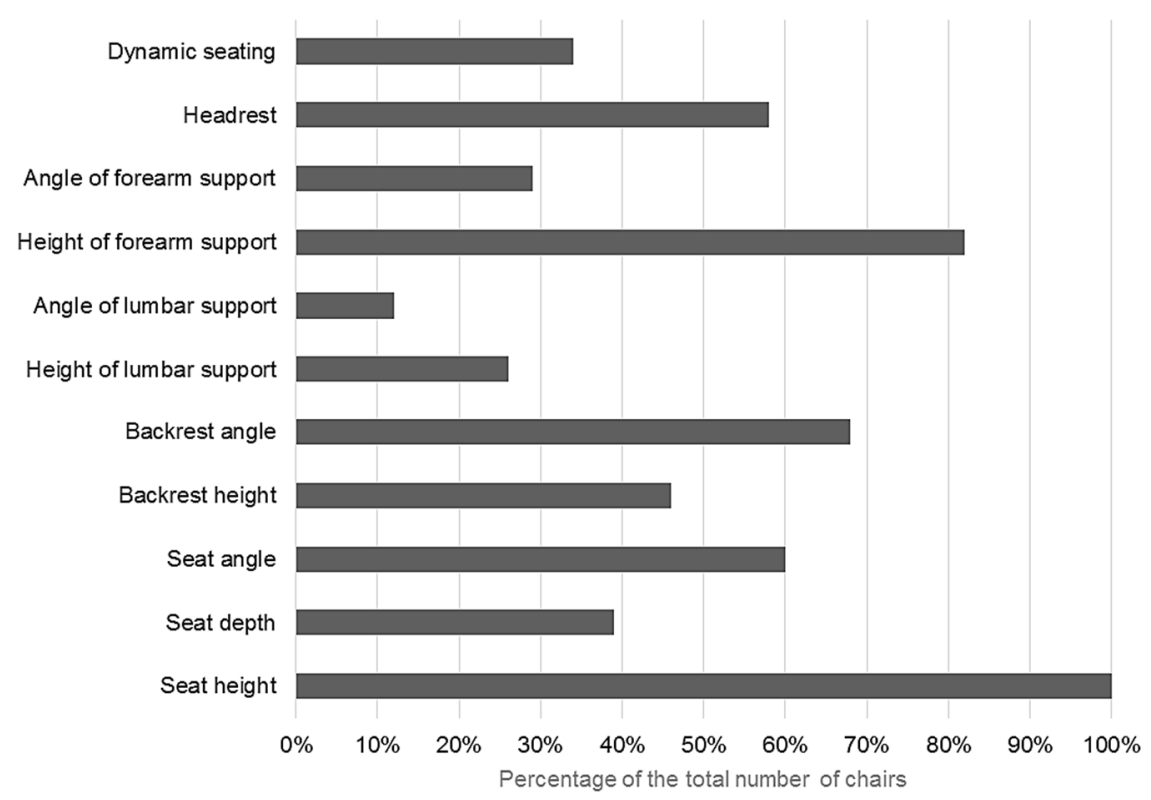

Fig. 4 Percentage of monitored parameters in the total number of monitored chairs

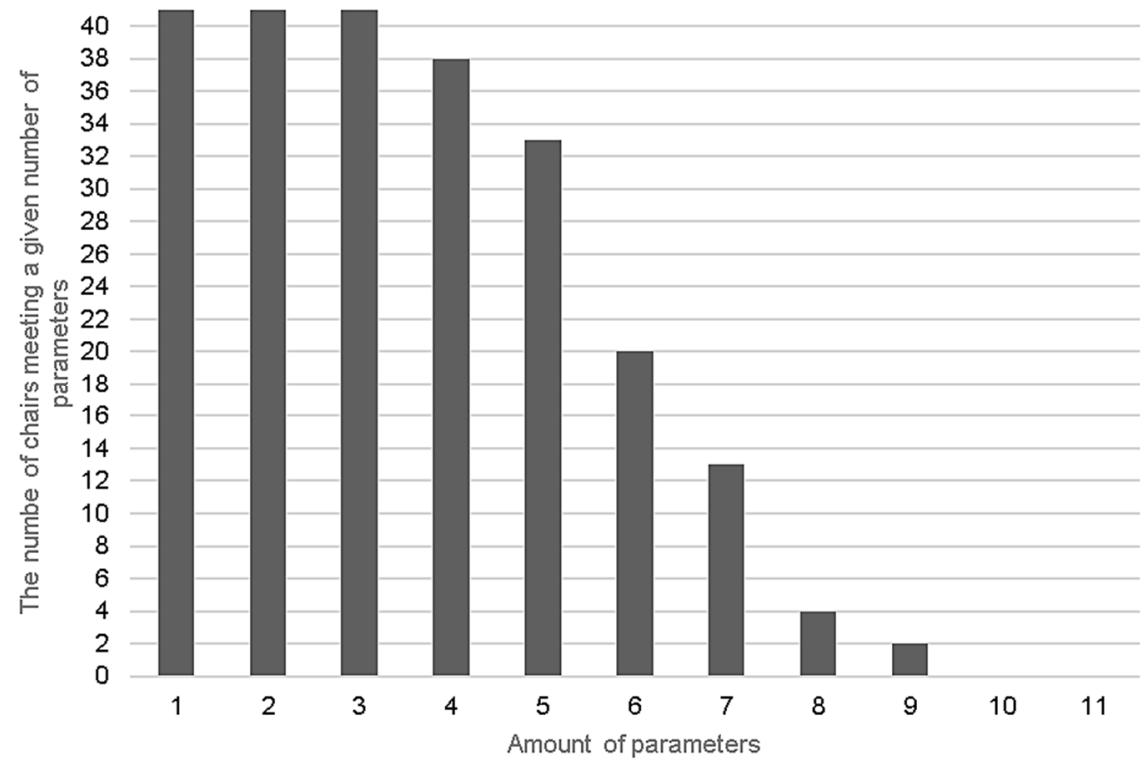

Fig. 5 The number of chairs meeting a given number of parameters 
These results show that none of the chairs offered on the Slovak market meets all the parameters that are necessary for reducing the static load. Only $5 \%$ of the chairs, which consists of 2 chairs out of a total of 41 , simultaneously met 9 out of 11 monitored parameters. The parameters met by more than half of the chairs were the adjustment of seat height and inclination, backrest inclination, height of the forearm supports, and the presence of the headrest. However, these elements are also common with conventional office chairs. The possibility of dynamic sitting was recorded with 14 chairs. However, the possibility of adjusting the height and depth of the lumbar support, the depth of the seat, or the angle of the forearm support was partly or wholly absent. Only $24 \%$ of chairs fulfilled the minimum requirements for the office chair defined by Slovak legislation. From more detailed analyses and discussions with experts, it can be stated that meeting the required parameters in one product is structurally and economically challenging. On the other hand, due to the increasing number of health problems resulting from the long-term performance of sedentary employment and static lifestyles, the focus must be on the development of such a product. However, it should be noted that the ergonomic chair itself does not eliminate static loads. In order to ensure the correct and healthy performance of a sedentary profession, it is necessary to take into account other elements of the workplace, including a work desk. Last, but not least, the human factor must be taken into account. This pilot survey was conducted for research to design a comprehensive intelligent adaptive dynamic workplace.

\section{CONCLUSION}

The results of the survey presented in this paper confirmed the fact that there is a growing number of sedentary professions in industrial enterprises. At the same time, the authors pointed out the health risks associated with this type of work activity. The survey was conducted in a manufacturing company supplying automotive components. Based on the analysis of the survey conducted, the expert team confirmed the defined hypothesis. Professions, whose performance is predominantly in the seated working position, have a majority representation in Slovakia. Up to $78 \%$ of all professions are sedentary professions in the industry where the survey was conducted. In Slovakia, it is up to $60 \%$ of all professions. From the perspective of industrial ergonomics, this is a very fundamental finding.

In the long-term performance of such activities, there is a static load and, after exceeding specific time intervals of static load, there is a significant decrease in human performance and manifestations of MSD. Therefore, the expert team continued to investigate ergonomic or health-labelled work chairs, which should alleviate the static load effect on the worker performing long-term sitting work. After analysing market research data, the expert team found that the chairs available on the market today do not have all the parameters that the ergonomic or health chairs should contain. In principle, they meet the basic requirements of adjustability, but only a fraction of the products allow dynamic seating, which is necessary to eliminate static loads. Office chairs using dynamic seating are designed based on a sitting on the therapeutic ball. However, long-term dynamic sitting on such a chair may cause the same difficulties as a static load because deep muscular structures responsible for maintaining balance are activated continuously, and for prolonged periods, there is over-load and subsequent pain. Based on these findings, the expert team 
recommends using the new technologies and based on data collection to determine the correct boundary of the dynamics of such a chair. It also recommends taking into account the effect of the human factor on the chair setting itself. The actual implementation of an ergonomic workplace chair does not guarantee its proper use. At the same time, it is necessary to combine the ergonomic chair with the heightadjustable table. Only a combination of a dynamic table and a dynamic chair ensures maximum adaptation to the anthropometric and anatomical characteristics of the worker. As research has shown, there is no chair in the market today that meets all the required parameters. Therefore, the expert team will continue to address this issue and research towards a complex dynamic workplace that should meet all the required parameters and at the same time include a management system that eliminates the impact of the human factor on the setting of workplace elements.

\section{ACKNOWLEDGEMENTS}

This work was supported by KEGA: KEGA 022ŽU-4/2018.

\section{REFEENCES}

Andersson, B. J., Ortengren, R., Nachemson, A.L., Elfström, G. and Broman H. (1975). The sitting posture: an electromyographic and discometric study. The Orthopedic clinics of North America, pp. 105-120.

Berlin, C., Adams, C. (2017). Production Ergonomics: Designing Work Systems to Support Optimal human Performance. London: Ubility Press, pp. 127-138.

Bršiak, V., Kotrbancová, M. and Bršiak, M. (2014). Prevencia a liečba bolesti chrbta. Púchov: Pro Benefit s.r.o.

Bubeník, P. (2004). A scheduling system for minimizing the costs of production. Strojniški vestnik. Journal of mechanical engineering, 50(5), pp. 291-297.

Decree of the Ministry of Health of the Slovak Republic, (2007). Health protection at work from physical workload, mental workload and sensory workload. Collection of Laws of the Slovak Republic, 542/2007, pp. 3876-3901.

Hatiar, K., Bršiak, V. (2018). Priemyselná revolúcia a prevencia t’ažkostí a chorôb podpornopohybového systému súvisiacich s prácou. In: Životné podmienky a zdravie. Bratislava: Univerzita Komenského v Bratislave, pp. 195-211.

Krajčovič, M., Plinta, D. (2012). Comprehensive Approach to the Inventory Control System Improvement. Management and production engineering review, 3(3), pp. 34-44.

Kvašňák, L. (2018). Pre dodávatelov automotive už nie sme atraktívni ako kedysi. [online] Trend. Available at: https://www.asociaciapz.sk/wpcontent/uploads/2018/05/Rozhovor-A.-Matusek_Trend.pdf [Accessed 03 Mar. 2019].

Regulation of the Government of the Slovak Republic, (2006). The minimum safety and health requirements for work with visual display units. Collection of Laws of the Slovak Republic, 276/2006, pp. 1616-1618.

Salvendy, G. (2012). Handbook of human factors and ergonomics. New Jersey: John Wiley \& Sons.

Sasik, R., Haluska, M., Madaj, R., Gregor, M. and Grznar, P. (2016). Development of the Assembly Set for the Logistic Transport Solution In: 55th International Conference of Machine Design Departments, Prague. Springer: Latest methods of construction design, pp. 81-86. 
Abstract: The issue of static load arises as a result of the optimization of activities and the natural development of industry towards digitization, implementation of technologies in the production process and elimination of manual work. Due to the inherent need to facilitate or completely replace manual work with machines, human activity focuses on the development, design, and management of these machines. This article presents the results of a survey of the representation of professions with the primary seated position in the selected industrial enterprise in comparison with the most frequently registered professions in specific sectors. Likewise, the authors also deal with the elimination of static loads arising from the performance of sedentary work through ergonomic chairs offered on the Slovak market. The paper presents the results of the market analysis focusing on the parameters of office chairs, which are marked as ergonomic or health. The findings of these surveys serve as one of the starting points for the design of a complex dynamic office workplace, which the authors deal with in research at the Department of Industrial Engineering at the University of Zilina.

Keywords: industrial engineering, ergonomics, office work, static load, ergonomic chairs 